\title{
The predose effect in thermoluminescent dosimetry
}

\author{
N Itoh ${ }^{1}$, D Stoneham ${ }^{2}$ and A M Stoneham ${ }^{3}$ \\ 1 1-7-35, Uenohigashi, Toyonaka, Osaka 560-0013, Japan \\ 2 Oxford Authentication Ltd, Boston House, Grove Technology Park, Oxon OX12 9FF, UK \\ ${ }^{3}$ Centre for Materials Research and Department of Physics and Astronomy, University College \\ London, Gower Street, London WC1E 6BT, UK
}

Received 4 October 2000

\begin{abstract}
We present a model of the predose effect of thermoluminescence in crystalline quartz in terms of known impurities and defect processes. It involves the recombination-induced dissociation of an aluminium-alkali complex $\left[\mathrm{Al} \mathrm{M}^{+}\right]$ and the reaction of an alkali $\left[\mathrm{M}^{+}\right]$with an activator $[\mathrm{X}]$, possibly $\mathrm{Ge}$, to make the former an efficient electron trap $\left[\mathrm{X} \mathrm{M}^{+}\right]$. This excitation-induced ionic process is a new feature, in addition to the simple carrier redistribution processes usually assumed, and is consistent with a number of experiments. The test dose detects $\left[\mathrm{X} \mathrm{M}^{+}\right]$, which is present in a concentration within the dynamic range of thermoluminescence measurements. Our model enables us to understand the enhanced sensitivity of the predose method, which has been widely used in archaeological and accident dosimetry, and to link it to established impurity and defect centres in $\alpha$-quartz.
\end{abstract}

\section{Introduction}

Thermoluminescence is well established as a tool for measuring radiation doses (McKeever 1985). It is especially valuable for retrospective dosimetry of historical events (Bailiff 1991), ranging from events involving nuclear weapons or nuclear accidents (Stoneham et al 1996, Bailiff 1999) to the baking of clay and hence the authentication of art ceramics (Fleming 1973, 1979, Aitken 1985). In such cases a natural dosemeter is needed, one which does not need to be specially installed in advance, prior to the dose. This is usually quartz, present naturally in fired ceramics; the historic dose obtained is the total dose since firing. Our discussion will relate specifically to quartz, although we believe there will be similar processes in the other materials which show predose effects (Bailiff 1994). We shall also concentrate specifically on fired quartz which has been heated to around $1000{ }^{\circ} \mathrm{C}$, thus eliminating the geological dose. Clearly, the quartz will vary in quality from one sample to another, for example through the varying concentrations of impurities like $\mathrm{Al}, \mathrm{Ge}, \mathrm{H}$ and $\mathrm{Na}$. This raises two issues. The first is that any explanation we propose, and any atomic processes we suggest, must use only those defects or impurities which will be present in any sample of quartz. The second issue is that of calibration and sensitivity. There must be a calibration of the thermoluminescence of any particular sample using a known laboratory dose. In its simplest form, the historic 
received dose (accrued dose $D$ ) is estimated from a thermoluminescent signal associated with that historic dose and from a thermoluminescent signal associated with a known dose applied in the laboratory (laboratory dose $L$ ).

There are various systematic procedures for making this comparison. Sometimes the thermoluminescent signals are strong enough for the careful worker to estimate the absorbed (historic) dose by the obvious method using ratios directly. However, often the direct approach is inappropriate, usually because there is a spurious (non-radiation-induced) thermoluminescence signal. If there is quartz in the sample, the 'predose' method may be used to overcome this limitation. Here the useful signal, at $110^{\circ} \mathrm{C}$ (the predose peak), can be enhanced by several orders of magnitude by using a more complex series of further irradiations and heatings of the irradiated specimen (activation). The result is an increase in sensitivity of the predose peak, related to an applied laboratory dose $(L)$, which is monitored at each stage using a 'test dose', $\tau$. The test dose is much smaller than the accrued dose $D$ (the sum of the natural dose and the laboratory dose, $L$ ) or the laboratory dose alone. The main effect of the 'activation' doses is to make more visible the effects of the doses to be measured. Despite a number of suggestions (Zimmerman 1971, Martini et al 1987, Yang and McKeever 1990) and discussions of aspects of the predose method (McKeever et al 1985, Halperin 1990, Halperin and Sucov 1991, 1993, Martini et al 1986, 1995), there has been no convincing explanation of the atomic and electronic processes involved in the predose behaviour in terms of the known properties of impurities and defects in quartz. The present paper addresses this point: we suggest specific processes, consistent with what is known of defects and impurities in quartz and the radiation response of quartz. A new feature is an ionic process resulting from electron-hole pair creation. We are therefore going beyond the discussions which develop phenomenological, purely electronic, trap models (e.g., Franklin et al 1995, Chen and Li 2000). Such models have value in rationalizing data, but are not readily linked to the atomistic information from the many detailed spectroscopic studies of defect and impurity species in quartz. In many cases, these phenomenological models fail to distinguish between thermal and optical energy levels of their hypothetical traps. In recognizing the role of an ionic process, our analysis shows we are discussing one of the many phenomena which may be described as materials modification by electronic excitation (Itoh and Stoneham (2000), especially chapters 6 and 7). We are able to give a kinetic analysis, and to show that the key features follow. Some uncertainties remain; nevertheless, we hope the understanding gained from this analysis will enable methods of this type, based on manipulation of defect populations, to be used more effectively and for a wider range of materials.

\section{Predose procedures}

We now describe a sequence of operations in applying one of the predose methods, multiple activation. It will be assumed that the sum of the historic and laboratory doses is sufficiently small for the sensitivity changes to be approximately linear. There are several variants of the method; for example, a more complex series of processes might be necessary when there are non-linearities because of other significant defect processes. We shall concentrate on the basic procedures.

We shall assume the sample has experienced a historic dose $D$. There is a sequence of processes, involving irradiation and heating to defined temperatures. The precise values of these temperatures depend on the heating rate; in the description below, the heating rate is $5{ }^{\circ} \mathrm{C} \mathrm{s}^{-1}$. The following sequence has been used extensively, and involves test doses in steps (1), (4) and (8). Similar sequences are described by Bailiff (1991), for example. 
(1) Apply a small test dose $\tau$, typically a hundredth of $D$.

(2) Heat to a temperature just above $110^{\circ} \mathrm{C}$. The intensity of the peak is $S_{0}$.

(3) Continue heating to a predetermined activation temperature (generally between $400{ }^{\circ} \mathrm{C}$ and $650^{\circ} \mathrm{C}$ ). This temperature of maximum activation of the predose peak is determined by another experiment.

(4) Cool to room temperature. Apply a further test dose $\tau$.

(5) Heat to $110^{\circ} \mathrm{C}$ or just beyond, observing a signal $S_{n}$. The difference in sensitivity, $S_{n}-S_{0}$, is proportional to $D$.

(6) Apply the known laboratory dose $L$.

(7) Heat to the activation temperature used in step 3.

(8) Cool to room temperature. Apply a further test dose $\tau$.

(9) Heat to $110{ }^{\circ} \mathrm{C}$, observing the signal $S_{n+L}$. The signal $S_{n+L}$ is proportional to $D+L$. The difference in signal intensities, $S_{n+L}-S_{n}$, is proportional to $L$. Overall, $D$ is given by

$$
D=L\left[S_{n}-S_{0}\right] /\left[S_{n+L}-S_{n}\right]
$$

assuming that there are no significant non-linearities, which would need more complex tests.

\section{Atomic processes involved in the predose phenomenon}

We shall discuss the atomic and electronic processes occurring in the three key steps, namely those during irradiation, those leading to the $110{ }^{\circ} \mathrm{C}$ thermoluminescence signal and those in the sensitization process at perhaps $500{ }^{\circ} \mathrm{C}$.

Any atomic processes which we suggest must be ones which can occur in any natural quartz. The impurities should therefore be common ones, like $\mathrm{Al}, \mathrm{Ge}, \mathrm{H}$ and $\mathrm{Na}$. We shall not claim that our suggestions define uniquely the only impurities and defect processes which can give predose behaviour, but we shall make conservative proposals which can be checked against other experiments and measurements. In particular, we shall assume that there is a reasonably large amount of $\mathrm{Al}$ present. This may only be tens or hundreds of parts per million, but we shall regard it as greater than the other concentrations we discuss, and never a limiting factor. This trivalent Al substituting at a silicon site will normally be compensated by alkali or hydrogen (Halliburton et al 1981). The total alkali concentration will be $c_{0}$. Petrov and Bailiff (1995) have noted the effects of annealing in different atmospheres, and suggest that oxygen vacancies might be involved. However, anneals in oxidizing atmospheres have a wide range of effects on impurities as well as defects. In most samples, those vacancies which have not trapped impurities are likely to be present in concentrations that are too low. We have not identified any promising defect processes consistent with knowledge of oxygen vacancies.

The atomic processes suggested are summarized in table 1, which describes the processes of detecting the historic dose. Extension to those of detecting laboratory dose is evident, since essentially the same processes are involved.

The main effect of radiation is to produce electrons and holes, rather than to create new lattice defects. The number of electron-hole pairs produced per unit volume is normally proportional to the absorbed energy $E$ per unit volume; an energy $W$, typically 2-3 times the bandgap, is needed to create each pair. 
Table 1. A model of the predose effect on thermoluminescence (TL) in a quartz. $Q$ represents an unknown electron trap and $R$ represents an unknown hole trap. There will normally be a significant number of electron and hole traps which compete for carrier capture. The 'Requirements' are those for the light output to be proportional to both the historical and test doses, and the 'Conditions' are those which ensure these requirements are met. The constants $a_{i}$ and $b_{i}$ determine the branching ratios at the different stages; $a_{1}=\alpha c_{0} \eta / N W$ (see equation (4)) and the other $a_{i}, b_{i}$ have to satisfy the 'Requirements' and 'Conditions' listed here.

\begin{tabular}{|c|c|c|c|c|}
\hline Procedure & Reaction & Yield & Requirement & Condition \\
\hline Historical dose $(D)$ & $\begin{array}{l}{\left[\mathrm{Al} \mathrm{M}^{+}\right]+\mathrm{e}^{-}+\mathrm{h}^{+} \rightarrow[\mathrm{Al}]+\left[\mathrm{M}^{+}\right]} \\
{[\mathrm{Q}]+[\mathrm{R}]+\mathrm{e}^{-}+\mathrm{h}^{+} \rightarrow\left[\mathrm{Q} \mathrm{e}^{-}\right]+\left[\mathrm{R} \mathrm{h}^{+}\right]} \\
\mathrm{e}^{-}+\mathrm{h}^{+} \rightarrow \text { recombination }\end{array}$ & $\begin{array}{l}a_{1} D \\
a_{2} D \\
a_{3} D\end{array}$ & $a_{1}=$ constant & $a_{1} \ll a_{2}+a_{3}$ \\
\hline Activation & {$[\mathrm{X}]+\left[\mathrm{M}^{+}\right] \rightarrow\left[\mathrm{X} \mathrm{M}^{+}\right]$} & $\approx a_{1} D$ & & \\
\hline Test dose $(\tau)$ & $\begin{array}{l}{\left[\mathrm{XM}^{+}\right]+[\mathrm{Al}]+\mathrm{e}^{-}+\mathrm{h}^{+} \rightarrow\left[\mathrm{MX}^{+} \mathrm{e}^{-}\right]+\left[\mathrm{Al} \mathrm{h}^{+}\right]} \\
{[\mathrm{Q}]+[\mathrm{R}]+\mathrm{e}^{-}+\mathrm{h}^{+} \rightarrow\left[\mathrm{Qe}^{-}\right]+\left[\mathrm{R} \mathrm{h}^{+}\right]} \\
\mathrm{e}^{-}+\mathrm{h}^{+} \rightarrow \text { recombination }\end{array}$ & $\begin{array}{l}b_{1} \tau \\
b_{2} \tau \\
b_{3} \tau\end{array}$ & $b_{1} \propto D$ & $b_{1} \ll b_{2}+b_{3}$ \\
\hline TL measurement & $\begin{array}{l}{\left[\mathrm{MX}^{+} \mathrm{e}^{-}\right] \rightarrow\left[\mathrm{MX}^{+}\right]+\mathrm{e}^{-}} \\
{\left[\mathrm{Alh}^{+}\right]+\mathrm{e}^{-} \rightarrow[\mathrm{Al}]+380 \mathrm{~nm} \text { photon }} \\
{\left[\mathrm{Rh}^{+}\right]+\mathrm{e}^{-} \rightarrow[\mathrm{R}]}\end{array}$ & $\begin{array}{l}b_{1} \tau \\
\frac{b_{1} \tau b_{1}}{b_{1}+b_{2}} \\
\frac{b_{1} \tau b_{2}}{b_{1}+b_{2}}\end{array}$ & Yield $\propto b_{1} \tau$ & $b_{2} \ll b_{1}$ \\
\hline
\end{tabular}

\subsection{Excitation-induced motion of alkali}

We shall assume that electron-hole recombination at aluminium with compensated alkali, $\left[\mathrm{Al} \mathrm{M}^{+}\right]$, induces a reaction:

$$
\left[\mathrm{Al} \mathrm{M}^{+}\right]+\mathrm{e}^{-}+\mathrm{h}^{+} \rightarrow[\mathrm{Al}]+\mathrm{M}^{+} .
$$

The creation of $[\mathrm{Al}]$ has been detected by EPR (the $\left[\mathrm{AlO}_{4}\right]$ centre) and $\mathrm{M}^{+}$has been detected through enhanced ionic conductivity (Jani et al 1983a, b). Thus, the alkali moves to a site from which it can be thermally activated.

If the concentration of alkali available for activation is $y$ (out of a total alkali concentration $c_{0}$ ) then we may assume the concentration of $\left[\mathrm{Al} \mathrm{M}^{+}\right]$centres is $c_{0}-y$. Provided that a condition that the concentration of the electrons and holes is governed by the recombination centres, or by electron and hole traps other than $\left[\mathrm{Al} \mathrm{M}^{+}\right]\left(a_{1} \ll a_{2}+a_{3}\right.$ in table 1$)$, the evolution of $y$ with energy $E$ absorbed per unit volume satisfies

$$
-\mathrm{d} y / \mathrm{d} E=(\alpha \eta / N W)\left(c_{0}-y\right)
$$

where $\eta$ is the efficiency of reaction (2), $N$ is the number of $\mathrm{SiO}_{2}$ molecules per unit volume, $W$ is the energy required to create an electron-hole pair and $\alpha$ is the number of sites visited by the excitation, or $N$ divided by the concentration of the effective recombination centres, which govern the electron-hole recombination.

The solution of this equation gives the number of alkali ions available for activation:

$$
y=c_{0}\{1-\exp (-\alpha \eta E / N W)\} .
$$

For small doses, $y$ is approximately $\alpha c_{0} \eta E / N W$. Comparison with the data of Martini et al (1987), for a specific quartz sample, gives us an estimate of $\alpha \eta$, for saturation begins at around $300 \mathrm{~Gy}$ (which is $3 \times 10^{4} \mathrm{rad}$ or $3 \times 10^{6} \mathrm{erg} \mathrm{cm}^{-3}$ or $1.8 \times 10^{18} \mathrm{eV} \mathrm{cm}^{-3}$ ). Care is needed in discussing saturation: one must distinguish between the increase in the $110{ }^{\circ} \mathrm{C}$ 
peak with absorbed dose in the absence of thermal sensitization, and the increase in response to a fixed test dose with prior absorbed dose and with thermal sensitization. In the latter case, non-linearities can be seen at much smaller doses, even at less than $1 \mathrm{~Gy}$. We shall use this lower figure, although we note that the values from the higher dose for saturation still lead to physically acceptable numbers.

Using a density $d$ of $2.65 \mathrm{~g} \mathrm{~cm}^{-3}$ and $W$ of $30 \mathrm{eV}$, we find $\alpha \eta$, the number of sites visited by the excitation multiplied by the efficiency of reaction (2), to be about $1.5 \times 10^{5}$. It follows that the concentration of the effective recombination centres is $10^{-8} / \eta$. We can also make estimates of the total numbers of centres which will be involved in the luminescence, since $y$ provides an upper bound.

The detection limit depends on the sample size and on other experimental parameters. Using the predose method, a typical minimum detectable absorbed dose is of order $10 \mathrm{mGy}$.

This is similar in order of magnitude both to figures given by Fleming and Thompson (1970) and in retrospective dosimetry of typical quartz extracted from brick (Bailiff 1995). Large test doses can be used if need be, since the response is linear in test dose.

This corresponds to a value of $y / c_{0}$ of order $10^{-4}$. If the conversion of that alkali available for activation is fully efficient, and if the total alkali is present in a concentration $c_{0} / N$ of order $10^{-5}$, then the atomic fraction of electron traps contributing to the luminescence at the detection limit is of order $10^{-9}$ and that at the saturation is $6 \times 10^{-6}$. These are reasonable numbers, within the dynamic range of thermoluminescence detected by the test dose, and less than the concentration of the effective electron traps. This inequality is important later.

\subsection{From alkali redistribution to thermoluminescence}

The effects of the radiation are recorded in the quartz by the processes induced by the radiation. In principle, the record of the dose is kept by the presence of the pairs of [Al] and $\left[\mathrm{M}^{+}\right]$. The stored dose can be detected by measuring the $110^{\circ} \mathrm{C}$ thermoluminescence peak only if both electrons and holes generated by the test-dose irradiation are stabilized by these pairs of traps; otherwise electron-hole recombination occurs, possibly at [Al]. We shall assume that the configuration of alkali influences its efficiency of electron trapping: the memory of the dose stored by the number of $[\mathrm{Al}]$ and $\left[\mathrm{M}^{+}\right]$pairs can be fully detected by thermoluminescence measurements only if alkalis are efficient electron traps, but we are aware that an alternative explanation is possible.

The current descriptions of the predose phenomena assume that hole traps are involved. This probably arose from the early observation (Thompson (1970), chapter 5) that there was exo-electron emission which correlated with the thermoluminescence. However, this correlation only implies that the same recombination events are involved. From thermoluminescence behaviour alone, it is not possible to decide whether electron traps or hole traps are responsible. It is only when one can make links to other types of experiment, notably electron spin resonance, that one can determine which carrier is involved. However, the sensitivity of spin resonance is less than that of the predose method. We have found that, when we relate the phenomena to the known and widely studied defect processes in quartz, the natural description is in terms of electron traps. The ideas of the earlier work carry over, largely unaltered apart from the change of carrier type.

Recognizing that $\left[\mathrm{M}^{+}\right]$is highly mobile, we believe the activation process modifies the configuration of the alkali impurities, which act as electron traps. In particular, we propose that heating to around $500{ }^{\circ} \mathrm{C}$ leads to the association of the alkali with a stabilizer $\mathrm{X}$, which we suggest is Ge:

$$
[\mathrm{X}]+\left[\mathrm{M}^{+}\right] \rightarrow\left[\mathrm{X} \mathrm{M}^{+}\right] .
$$


Thus the full electron trap might be $\left[\mathrm{Ge} \mathrm{Na}^{+} \mathrm{e}^{-}\right]$. We shall assume that the yield of the reaction is close to unity, although this is not a strong requirement. Clearly there may be some pre-existing electron traps inducing $110{ }^{\circ} \mathrm{C}$ thermoluminescence, prior to stage 2 , for example. These give rise to the luminescence $S_{0}$ and must be subtracted, as noted above.

The involvement of the reaction (2) in the predose effect is supported by following experimental observation. First, the sweeping out of alkali by electrodiffusion reduces the predose effect (Martini et al 1987). According to EPR measurements, most unswept aluminium atoms are in the form of $\left[\mathrm{Al} \mathrm{M}^{+}\right]$, while they are associated with $\mathrm{OH}$ in swept specimens (Halliburton et al 1981). Secondly, the radiation-induced conductivity of ionic character (Hughes 1973, Jain and Nowick 1982a, b, Martini et al 1986) has been interpreted as arising from the radiation-induced release of alkali ions from $\left[\mathrm{Al} \mathrm{M}^{+}\right]$.

Given that the test doses $\tau$ are very much smaller than either the historic dose $D$ or the laboratory dose $L$, what does the test dose do? The test doses have no significant effect on the alkali. What they do is to generate electrons and holes, so the electrons are trapped by $\left[\mathrm{X} \mathrm{M}^{+}\right]$ and holes are trapped by $[\mathrm{Al}]$, resulting in $\left[\mathrm{Al} \mathrm{h}^{+}\right]$and $\left[\mathrm{X} \mathrm{M}^{+} \mathrm{e}^{-}\right]$. In principle, the electrons and holes could recombine instead, or be trapped at other defects like dislocations (see table 1). As long as the concentration of the $[\mathrm{Al}]$ and $\left[\mathrm{X} \mathrm{M}^{+}\right]$pairs is small enough that those traps do not overwhelm the other traps or recombination centres, e.g., smaller than the concentration of the effective recombination centres, the concentrations of $\left[\mathrm{Al} \mathrm{h}^{+}\right]$and of $\left[\mathrm{X} \mathrm{M}^{+} \mathrm{e}^{-}\right]$pairs is proportional to the test dose (see table 1). We can confirm this is so.

Using the concentration of the effective recombination centres evaluated for reaction (2), we see that a linear response to $\tau$ is expected below the saturation level stated earlier. In this range, the concentration of $\left[\mathrm{Al} \mathrm{h}^{+}\right]$and $\left[\mathrm{X} \mathrm{M}^{+} \mathrm{e}^{-}\right]$pairs is proportional to both $D$ and $\tau$.

For systems typical of those to which predose methods are applied, low concentrations of impurities will be present in considerable variety. The actual concentrations are not known, or easily knowable, and detailed quantitative kinetic arguments are not helpful. Nor are the concentrations easily changed without side effects. Little is to be gained, therefore, by fitting results to rate equations.

What can be said about the $110{ }^{\circ} \mathrm{C}$ luminescence? The basic luminescence process, we believe, is this (where $\mathrm{X}$ is may well be $\mathrm{Ge}$, and $\mathrm{M}$ is the alkali):

$$
\left[\mathrm{Al} \mathrm{h}^{+}\right]+\left[\mathrm{X} \mathrm{M}^{+} \mathrm{e}^{-}\right] \rightarrow[\mathrm{Al}]+\left[\mathrm{X} \mathrm{M}^{+}\right]+380 \mathrm{~nm} \text { photon }
$$

in which we assume that $\mathrm{T}$, the hole trap, is $\mathrm{Al}$; this is discussed below. As written, the equation suggests direct donor-acceptor recombination. Perhaps more probable is the thermal ionization of one of the centres (perhaps $\left[\mathrm{X} \mathrm{M}^{+} \mathrm{e}^{-}\right]$) followed by radiative recombination at the other $\left(\left[\mathrm{Al} \mathrm{h}^{+}\right]\right)$. If this second description is correct, $\left[\mathrm{Ge} \mathrm{Na}^{+} \mathrm{e}^{-}\right]$loses its trapped electron at $110{ }^{\circ} \mathrm{C}$. This decay at room temperature will correspond to the 146-minute lifetime (Fleming 1969). The intensity of the thermoluminescence is proportional to the concentration of $\left[\mathrm{X} \mathrm{M}^{+} \mathrm{e}^{-}\right]$, if hole traps other than $\left[\mathrm{Al} \mathrm{h}^{+}\right]$are negligible. Further, if electrons are released from $\left[\mathrm{Ge} \mathrm{Na}^{+} \mathrm{e}^{-}\right]$at $110{ }^{\circ} \mathrm{C}$, some of the electrons may be captured at other, slightly deeper, traps; on further heating, these, in turn, can release their electrons to give the weaker, higher-temperature predose peaks. These weaker, higher-temperature predose peaks are observed.

There is circumstantial evidence for the luminescence centre being [Al]. First, the EPR signals due to $\left[\mathrm{Al} \mathrm{h}^{+}\right]$are observed after $\mathrm{x}$-ray irradiation (Halliburton et al 1981, Martini et al 1995) and annihilated slowly at room temperature, where phosphorescence at $380 \mathrm{~nm}$ is observed (Martini et al 1986). Secondly, x-ray-induced luminescence at $380 \mathrm{~nm}$ is emitted during irradiation (Alanso et al 1983, Halperin and Sucov 1993). Its intensity is reduced by heating that causes activation of the predose effect, indicating that electron-hole recombination 
at [Al] dominates, if electrons are not stabilized by electron traps that give rise to the thermoluminescence. Thirdly, the thermoluminescence intensity is a superlinear function of the dose (Yang and McKeever (1990); see also Bailiff (1994) concerning fired quartz from pottery), suggesting multiple steps for producing trapped electrons and holes that give rise to the thermoluminescence. According to the present model, reactions (2), which dissociate alkalis from $\left[\mathrm{Al} \mathrm{M}^{+}\right]$, and reaction (5), which supplies alkali with electrons, are needed. With a given amount of the test dose, the thermoluminescence intensity is a linear function of the historic or laboratory dose, as observed, at least at doses less than a few Gy. Fourthly, almost the same phenomenon is observed by applying the 'historic dose' and 'test dose' at liquid nitrogen temperature; in this case, activation can be carried out at lower temperatures (Halperin et al 1986, Halperin 1990). The thermoluminescence emission occurs at $380 \mathrm{~nm}$ also, although the thermoluminescence peaks are observed at lower temperatures. It appears that the electron traps vary depending on irradiation and activation temperatures but the recombination occurs at the same site: [Al].

Clearly, possibilities for the final luminescence process include intersite recombination and luminescence on electron capture. However, there is also a third possibility. The emission of luminescence by defect recombination is a well established concept for alkali halides: the recombination of an $\mathrm{H}$ centre (an interstitial halogen atom), released from a trap on an alkali impurity, with an F centre (a halogen vacancy) leads to thermoluminescence near liquid nitrogen temperature (Tanimura et al 1974). It has been argued further that several highertemperature thermoluminescence peaks are due to the recombination of the F centres with the $\mathrm{H}$ centres released from various types of trap (Alvarez Rivas 1980). There are two ways for luminescence to be emitted by defect recombination: direct, or via generation of electrons or holes upon the thermal release of defects. The direct process is feasible when the ground state is ionic while the separated defect pairs are neutral or in an excited state, as is the case for $\mathrm{F}-\mathrm{H}$ pairs and probably for the $\left[\mathrm{Al} \mathrm{M}^{+}\right]$centres, although a detailed calculation is needed for the latter. The defects are effectively in an excited state as they approach, and reach the ground state by emitting photons with a certain probability.

The $110{ }^{\circ} \mathrm{C}$ peak is known to be enhanced not only by $\mathrm{x}$ - or $\gamma$-irradiation but also by photo-excitation, although the efficiency is low (Kaylor et al 1995). However, there is no photoactivated sensitization: there is no increase in absorbed intensity in response to a fixed test dose with prior absorbed dose and thermal activation. This, presumably, means that light does not affect the process involving alkali motion. It has been shown that the increase of the $110^{\circ} \mathrm{C}$ peak is accompanied by the decrease of a thermoluminescence peak at $325^{\circ} \mathrm{C}$, a phenomenon known as photo-transferred thermoluminescence (PTTL), and that photo-excitation induces optically stimulated luminescence (OSL), the intensity of which decreases gradually as the transfer proceeds. We believe that these observations can be explained by our model, which assumes that the dose for the $110{ }^{\circ} \mathrm{C}$ peak is stored by trapped electron-hole pairs and the historic or laboratory dose is stored by the separated $[\mathrm{Al}]$ and $\left[\mathrm{M}^{+}\right]$pairs. It is likely that a part of the energy stored by $[\mathrm{Al}]$ and $\left[\mathrm{M}^{+}\right]$is emitted as photons by their recombination, triggered either by thermal or photo-excitation. Thus, without predose treatment, the sample should exhibit higher-temperature thermoluminescence or OSL. Photo-excitation for PTTL plays two roles: it induces the recombination of $[\mathrm{Al}]$ and $\left[\mathrm{M}^{+}\right]$, eliminating a proportion of the $[\mathrm{Al}]$ and $\left[\mathrm{M}^{+}\right]$pairs stored by the historic or laboratory dose, and it supplies electrons to alkalis, as the test dose does. PTTL accompanied by OSL has not been fully understood on the basis of the conventional model of thermoluminescence that assumes that it is the thermal release of charge carriers that determines the peak temperature (McKeever and Morris 1994, Wintle and Murray 1997). We note that Magagnini (2000) has carried out a density functional calculation for the ground state of $\mathrm{SiO}_{2}:(\mathrm{Al}, \mathrm{M})$. 


\section{Summary}

We have suggested a model of the predose effect for thermoluminescence in $\alpha$-quartz. The model satisfies two important constraints. First, it explicitly links the predose processes to those impurities and defects which are almost certain to be present in any sample of natural $\alpha$-quartz. Secondly, it is robust, in the sense that the concentrations of the impurity and defect species can vary quite widely whilst allowing predose behaviour. We find it necessary to include a step in which electron-hole pairs drive an ionic process, and this differentiates the model from previous ones, which supposed only electronic carrier redistribution was involved. Subject to some simple assumptions, all apparently reasonable, the model satisfies the requirement that the light output after historical and test doses is proportional to both doses. One of the conditions is that there exist impurities which act as recombination centres and have concentrations higher than Al are conceivable, e.g., Ge (Jenkins et al 1987, Hayes and Jenkins 1988). Thus, the condition is not unrealistic.

According to the model, the predose effect uses thermoluminescence from the test dose to detect the products of recombination-induced reaction taking place under the historic dose. Their stability ensures the accuracy of the historic dose evaluation. Thermoluminescence involving lower-temperature peaks can detect the number of traps more sensitively: the instability of trapped carriers released at low temperature is not the major concern in this technique.

We presume that there are many other recombination-induced reactions that are induced in solids under ionizing radiation and high stabilities. These other reactions might be used for dosimetry and dating, when subjected to high-sensitivity detection. Other high-sensitivity detection methods, including those of optically stimulated recombination luminescence and exo-electron emissions of electrons trapped by the products, could be promising techniques for dosimetry and dating.

\section{Acknowledgments}

We should like to thank Ian Bailiff for helpful discussions. We should also like to express our appreciation to Professor William Hayes for his major contributions to the understanding of defects and defect processes in $\alpha$-quartz and many other systems.

\section{References}

Aitken M J 1985 Thermoluminescence Dating (London: Academic)

Alanso P J, Halliburton L E, Kohnke E E and Bossoli R B 1983 J. Appl. Phys. 545369

Alvarez Rivas J 1980 J. Physique Coll. 41 C6 353

Bailiff I K 1991 Scientific Dating Methods ed H Y Göksu (Brussels-Luxembourg: ECSC, EEC, EAEC) pp 155-73

Bailiff I K 1994 Radiat. Meas. 23471

Bailiff I K 1995 Radiat. Meas. 24507

Bailiff I K 1999 Radiat. Protect. Dosim. 84411

Chen G and Li S H 2000 J. Phys. D: Appl. Phys. 33437

Fleming S J 1969 Thesis University of Oxford

Fleming S J 1973 Archaeometry 1513

Fleming S J 1979 Thermoluminescence Techniques in Archaeology (Oxford: Oxford University Press)

Fleming S J and Thompson J 1970 Health Phys. 18567

Franklin A D, Prescott J R and Scholefield R B 1995 J. Lumin. 63317

Halliburton L E, Koumvakalis N, Markes M E and Martin J J 1981 J. Appl. Phys. 523565

Halperin A 1990 J. Phys. Chem. Solids 51303

Halperin A, Jani M G and Halliburton L E 1986 Phys. Rev. B 345702 
Halperin A and Sucov E W 1991 J. Phys. Chem. Solids 521039

Halperin A and Sucov E W 1993 J. Phys. Chem. Solids 5443

Hayes W and Jenkins T J L 1988 J. Phys. C: Solid State Phys. 212391

Hughes R C 1973 Phys. Rev. Lett. 301333

Itoh N and Stoneham A M 2000 Materials Modification by Electronic Excitation (Cambridge: Cambridge University Press)

Jain H and Nowick A S 1982a J. Appl. Phys. 53477

Jain H and Nowick A S 1982b J. Appl. Phys. 53485

Jani M G, Bossoli R B and Halliburton L E 1983a Phys. Rev. B 272285

Jani M G, Halliburton L E and Konke E E 1983b J. Appl. Phys. 546321

Jenkins T J L, Koppitz J, Shirmer O F and Hayes W 1987 J. Phys. C: Solid State Phys. 20367

Kaylor R, Feathers J, Hornyak W F and Franklin A D 1995 J. Lumin. 651

Magagnini M 2000 Phys. Rev. B 621524

Martini M, Paleari A, Spinolo G and Vedda A 1995 Phys. Rev. B 52138

Martini M, Spinolo G and Vedda A 1986 J. Appl. Phys. 601705

Martini M, Spinolo G and Vedda A 1987 J. Appl. Phys. 612486

McKeever S W S 1985 Thermoluminescence in Solids (Cambridge: Cambridge University Press)

McKeever S W S, Chen C Y and Halliburton L E 1985 Nucl. Tracks 10489

McKeever S W S and Morris M F 1994 Radiat. Meas. 23301

Petrov S A and Bailiff I K 1995 Radiat. Meas. 24519

Stoneham D, Bailiff I K, Botter-Jensen L, Goeksu Y, Jungner H and Petrov S 1996 Retrospective dosimetry: the development of an experimental methodology using luminescence techniques Proc. 1996 Conf. on the Radiological Consequences of the Chernobyl Accident (Minsk) ed A Karaoglou, G Desmet, G N Kelly and H G Menzel (Brussels: European Commission) (EUR 16554 EN)

Tanimura K, Fujiwara M, Okada T and Suita T 1974 Phys. Lett. A 50301

Thompson J 1970 The influence of previous irradiation on thermoluminescence sensitivity PhD Thesis University of Oxford

Wintle A G and Murray A S 1997 Radiat. Meas. 27611

Yang X H and McKeever S W S 1990 J. Phys. D: Appl. Phys. 23237

Zimmerman J 1971 J. Phys. C: Solid State Phys. 43277 